\title{
OBSERVATIONS ON THE BIOLOGY OF ACHAEARANEA TESSELATA (ARANEAE: THERIDIIDAE) ${ }^{1}$
}

\author{
By William G. Eberhard \\ Depto. de Biología, \\ Universidad del Valle \\ Cali, Colombia
}

Achaearanea tesselata is relatively common in trees and bushes in urban Cali, Colombia (el. $1000 \mathrm{~m}$ ) and the surrounding countryside of the same elevation which Espinal ( 1968) classifies as a dry tropical forest zone (annual rainfall about $900 \mathrm{~mm}$ ). As it appears that nothing is known of the biology of this species (Levi, pers. comm.), it seems worthwhile to publish brief descriptions of some of its more outstanding characteristics.

\section{Webs}

The webs were usually isolated, although occasionally several occurred in a single bush. Each web consisted of a horizontal, more or less circular platform, with thick mesh above and thin mesh below (Fig. Ia). A piece of leaf or other detritus was nearly always suspended in approximately the middle of the mesh above the sheet, and the spider rested within or just below this object. Usually the shelter was a curled leaf, and spider rested inside, out of sight from above or the side. No consistent differences were noted between webs of small and large spiders.

When the web threads were coated with fine powder (cornstarch) and then blown and jolted, all the powder came off, thus demonstrating that none of the web threads were sticky. Although the platform portion of the web did not have an obviously regular structure, there appeared to be some limits to the diameters of the holes beween threads (Fig. Ib).

The spiders were capable of building a more or less complete web in a single night, but were occasionally found on incomplete webs. One morning after a very strong rain in the night which almost certainly destroyed all webs, several spiders were found on webs with both mesh and platform of clean, apparently new threads, but one

\footnotetext{
${ }^{1}$ I thank Dr. H. W. Levi for identifying specimens and furnishing additional information. This study was supported by a grant from the Fondo Universitario para la Investigación of the Universidad del Valle.

Manuscript received by the editor March 1, 1972.
} 

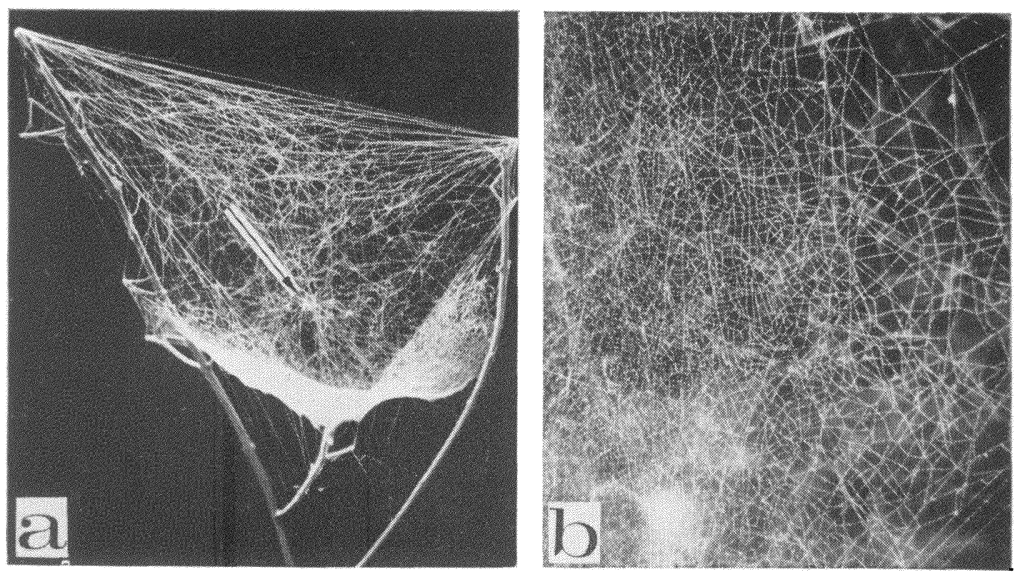

Fig. 1. a) Web of adult female Achaearanea tesselata. Arrow indicates position of spider; there is no leaf or other detritus included in the retreat of this web. Web platform is about $15 \mathrm{~cm}$ across.

b) Closeup of threads in right edge of platform of the web in $a$. Spaces between threads are larger near the edge of the platform.

web had only a mesh. One spider kept in captivity built a loose mesh on the first night (during which it was apparently disturbed by an observation light), added a platform and more mesh on the second night (undisturbed), and extended the platform on the third.

One individual deserted one site in the laboratory and built in another. It left the first web intact, indicating that these spiders may be unable to re-utilize silk used in previous webs as many araneids do (see Breed et al 1964 for example). Turnbull found that Achaearanea tepidariorum also left deserted webs more or less intact (pers. comm.).

\section{Attacks on prey}

Achaearanea tesselata rested in its retreat in the mesh above the platform both day and night. A spider's first response to prey in the web was almost always to drop from this position to the underside of the platform. That is, it fell through the platform, but held onto it after falling through. These events happened too quickly for me to observe how the spider managed to catch the platform as it fell through. There was no obvious hole in the platform below the shelter either before or after a fall, and spiders could be induced to fall through and catch the platform at other points as well.

When the prey was on the platform, the spider usually rushed 
directly to it and began wrapping it, or bit it immediately if it was small. After wrapping a larger prey, the spider bit it, cut a hole in the platform around it, climbed into the mesh above, and carried it dangling from a line held by one leg IV to the retreat where it often wrapped it further before beginning to feed. If the prey was detained in the mesh above the platform, the spider shook the web until it fell, or climbed through the platform and attacked it in the mesh above. Holes cut in the platform to extract prey were filled the next night so as to be nearly indistinguishable from the surrounding platform.

It was not uncommon to find immatures in the webs of adult females, and these were seen clustered around and apparently feeding on prey caught in these webs. This type of behavior is apparently common in theridiids (Kullmann 1969, Shear 1970).

\section{Discussion}

The web of $A$. tesselata is very distinct from that of the common house spider $A$. tepidariorum, but is apparently similar to those of an Achaearanea sp. from Afganistan (Kullmann 1970) and A. disparata (Darchen 1968 in Kullmann 1970). Kullmann's drawing of the web of the Achaearanea sp. from Afganistan differs from $A$. tesselata webs in having sticky threads radiating from the spider's retreat and ending just above the platform, but such lines are not distinguishable in his photograph, nor are they mentioned in his discussion. The $A$. tepidariorum web is a mesh with no well-defined platform, has drops of sticky fluid on lines attached to the ground, and has no well-defined retreat, the spider sitting near or at the edge of the web during the day (McCook I889, Kaston 1948, pers. obs.). The $A$. tepidariorum web seems designed to capture mainly walking prey, while the $A$. tesselata type web seems designed exclusively for flying prey.

The "platform with mesh above and below" design of $A$. tesselata's web is the basic plan of the webs of several distantly related spiders including Diguetia (Diguetidae) (Cazier and Mortenson 1962), Cyrtophora (Araneidae) (McCook I889), and several genera of linyphiids (see Nielson I928, and Kaston I948 for example). Greater thickness of the upper mesh and the particular form of the platform, a gently sloping dish with downward projecting "pimples", are common in these genera, occurring in the webs of Cyrtophora (Kullmann 1958), Diguetia (Eberhard 1967, although neither the slope nor the pimples are especially clear in the photograph), and the linyphiid Frontinella (Kaston 1948), as well as in webs of $A$. tesselata. However $C y r t o-$ 
phora and at least some of the linyphiids place sticky silk in their webs - Cyrtophora in the mesh just above the platform (Kullmann 1958), and the linyphiids in the sheet and the mesh above (Kullmann 1964, pers. obs.). Diguetia albolineata and D. canities webs are similar to $A$. tesselata webs in lacking sticky silk (pers. obs.). Achaearanea tesselata is unique in resting above the platform and dropping through it to attack prey, as all the others rest on surfaces connected to the lower surface of the platform.

\section{REFERENCES}

Breed, A. L., V. D. Levine, D. B. Peakall, and P. N. Witt

1964. The fate of the intact web of the spider Araneus diadematus (C1). Behaviour 23: 43-60.

Cazier, M. A., and M. A. Mortenson

1962. Analysis of the habitat, web design, cocoon and egg sacs of the tube weaving spider Diguetia canities (McCook). Bull. So. Cal. Acad. Sci. $61(2): 65-88$.

Eberhard, W. G.

1967. Attack behavior of diguetid spiders and the origin of prey wrapping in spiders. Psyche 74(2): 173-181.

ESPINAL, L. S.

1968. Vision ecológica del Departamento del Valle del Cauca. Universidad del Valle, Cali, Colombia.

KASTON, B. J.

1948. Spiders of Connecticut. Conn. Geol. Nat. Hist, Survey. Bull. no. $70: 9-874$.

Kullmann, E.

1958. Beobachtung des Netzbaues und Beitrage zur Biologie von Cyrtophora citricola Forskal (Araneae, Araneidae). Zool. Jb. (Abt. Syst) 86: 181-216.

1964. Neue Ergebnisse über den Netzbau und das Sexualverhalten einiger Spinnenarten (Cresmatoneta mutinensis, Drapestica socialis, Lithyphantes paykullianus, Cyrtophora citricola). Zeit. zool. Syst. Evolutionsforsch. 2: 41-122.

1968. Sociale Phaenomene bei Spinnen. Insectes Sociaux 15(3): 289298.

1970. Bemerkenswerte Konvergenzen im Verhalten Chibellater und Ecribellater Spinnen. Freunde Kolner Zoo $13(4)$ : 123-150.

$\mathrm{McCooK}, \mathrm{H}$. C.

1889. American spiders and their spinningwork. Vol. I. Webs and Nielson, E. Nests, published by the author, Philadelphia.

1928. The biology of spiders. Vol. 2. Levin \& Munksgaard, Copenhagen.

SHEAR, W.

1970. The evolution of social phenomena in spiders. Bull. Brit. Arach. Soc. $1(5)$ : 65-76. 

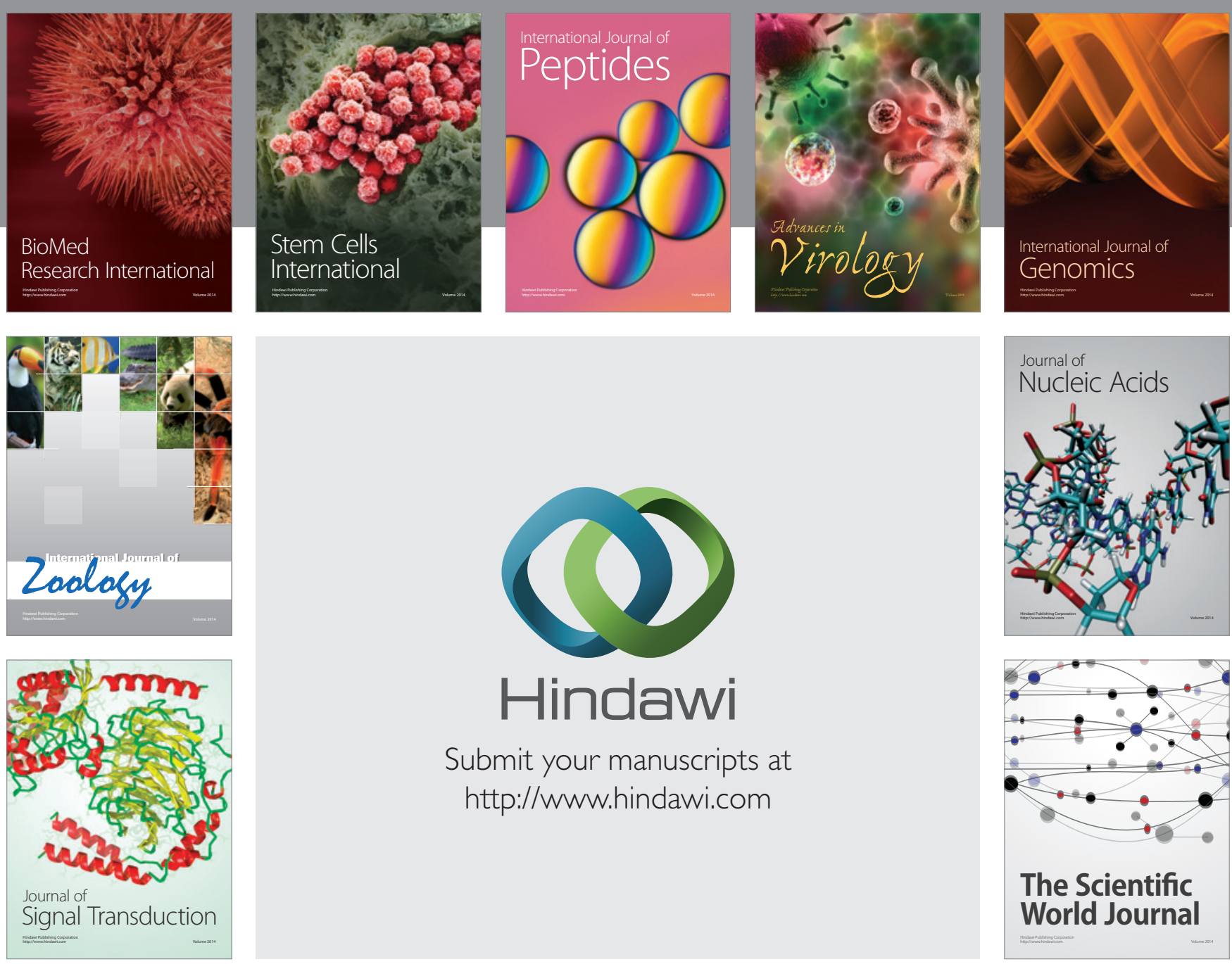

Submit your manuscripts at

http://www.hindawi.com
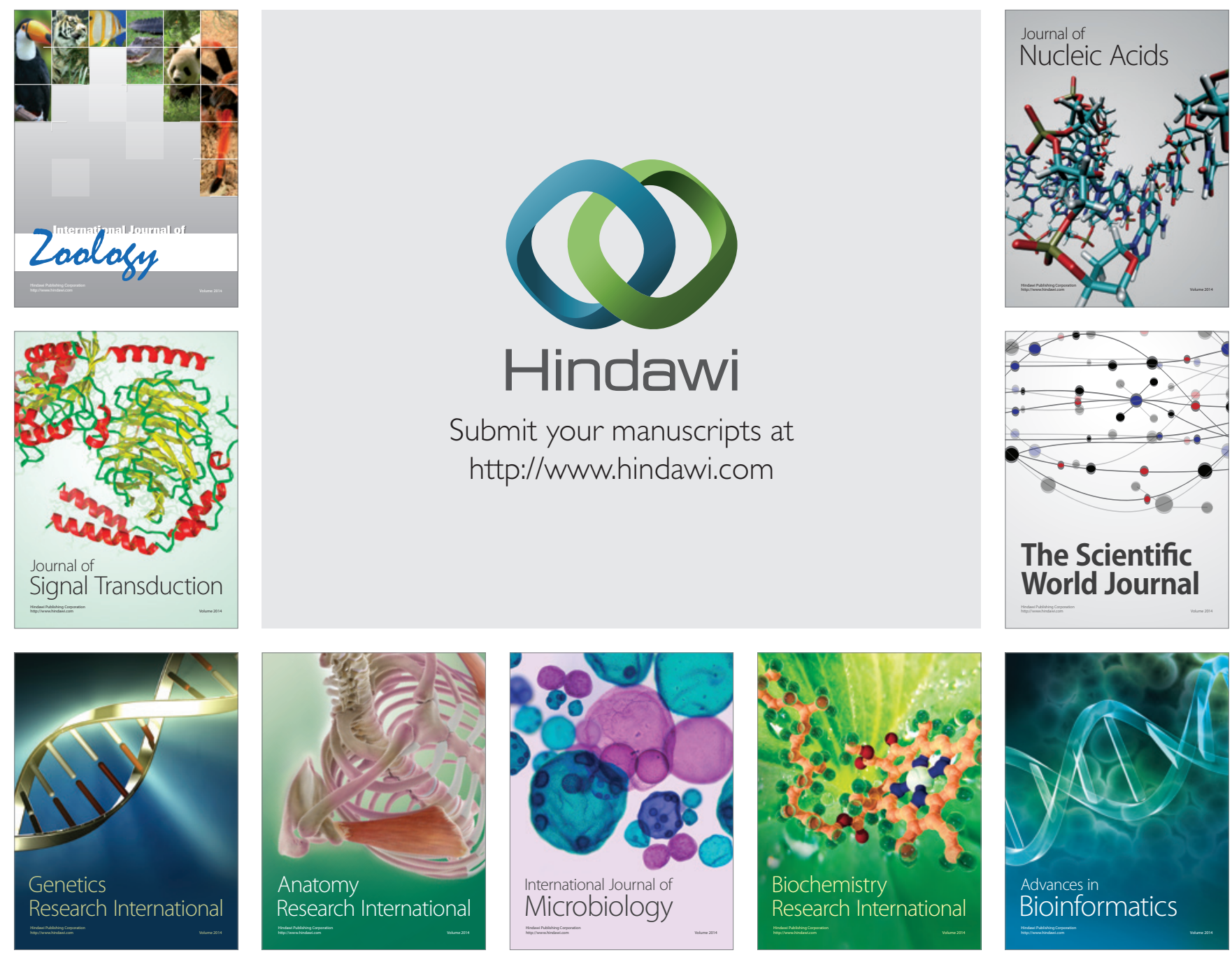

The Scientific World Journal
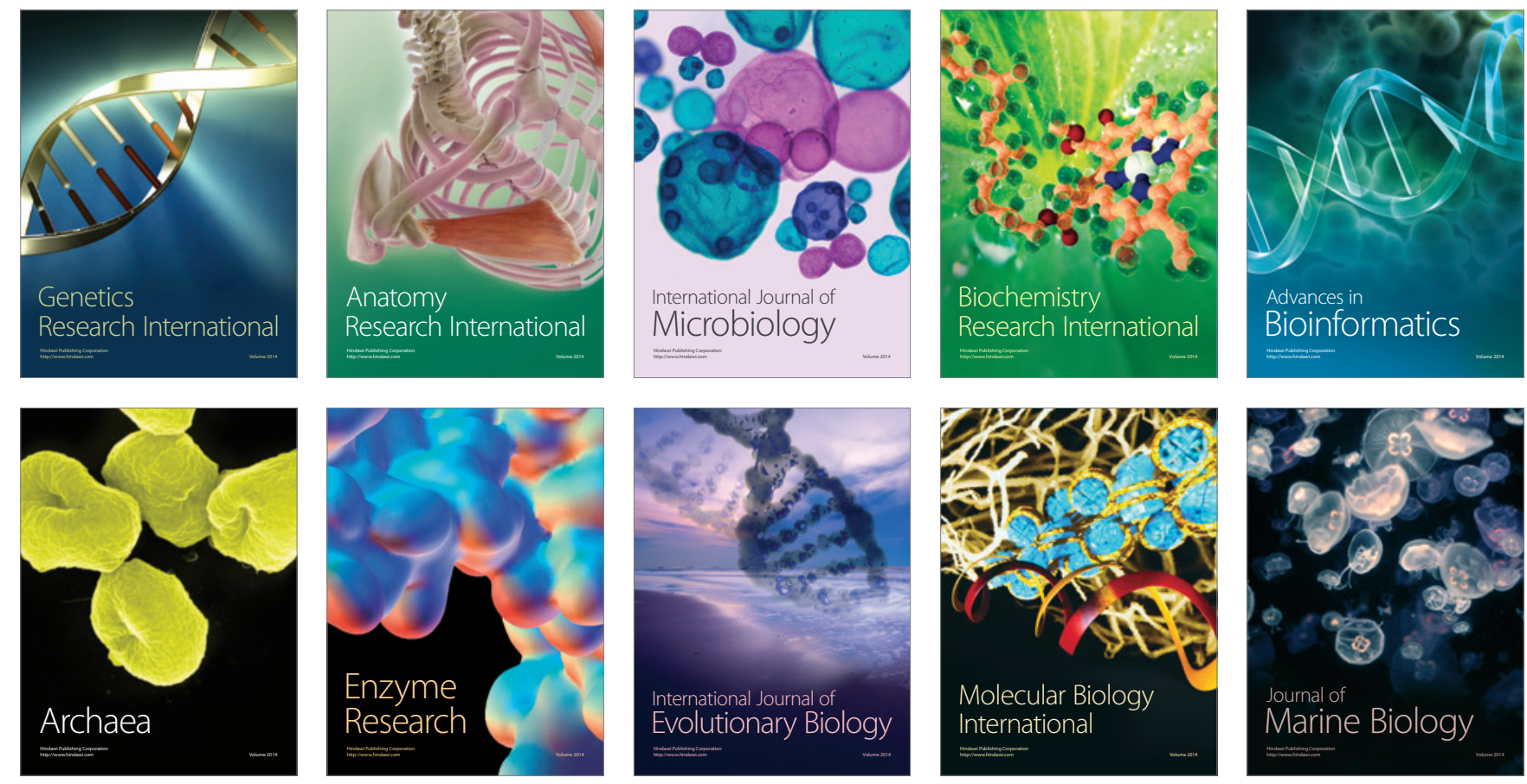